\title{
DESIGN OF PRESS TOOL FOR BOTTOM TANK IN AN AIR CONDITION UNIT
}

\author{
Sanjay Kumar S.M. ${ }^{1}$, D.P.Girish ${ }^{2}$ \\ ${ }^{1}$.Associate Professor, Department of Mechanical Engineering, Brindavan College of Engineering, Bangalore- \\ 560063. \\ sanjay20376@gmail.com \\ 2. Professor \& HOD, Department of Mechanical Engineering, Govt. Engineering College, Ramanagara, Karnataka., \\ omganesha16@gmail.com
}

\begin{abstract}
Bottom tank (Heater core) is made up of multilayered Aluminium strip. The capacity was 25 tons mechanical press for all the tools. Even though the tonnage requirement of the tools are less, the available press was for 25 tonnes. The main objective of this work is to design press tool for 25 tonnage capacity of the machine. The different drawing tools required are draw tool, setting tool, trimming tool, skirt draw tool etc. so that component is formed in a single shot. Theoretical calculation has to be carried out before doing design analysis. Tonnage capacity must be checked with necessary equations. Tools has to be selected as per DME, HASCO standards.
\end{abstract}

Keywords: Aluminium, Tonnage, Draw Tool, Setting Tool, etc.,

\section{INTRODUCTION}

The modern car, radio and television sets, clocks and watches, house hold wares and office furniture are all examples where press tools are used in varying degrees permitting the marketing of a complete series of products quickly and cheaply to bring them within the purchasing power of the public.

More and more it has become the practice to produce from sheet metal by some form of pressing process, workpieces that would have been made from bar, forging or casting two or three decades ago. Also, the handling of both strip material and semi-finished components has assumed an importance simply because fast and efficient movement means cheap products from operators who do not suffer fatigue from the handling of awkward or heavy components. However, it should not be forgotten that press design has made many advances in recent years in common with, for example, the machine tool industry, and machines are now available that are capable of withstanding the heavy stresses set up in many modern production process.

From this encouraging picture it may come something of a surprise to realize that in press work there are often factors, particularly in bending and drawing process where successful results are obtained only through the extensive experience of a tool designer and not from information derived from text books. Four factors are essential contributions to first-class press work.i.e Good operation planning, Excellent tool design, Accurate tool making and Knowledgeable press setting.
Automobile industry in India is growing at a faster pace. This phenomenon is being seen whole over the world and in the recent years, India is also a good customer for the big automobile manufactures. Different models of vehicles are on the road every month. Each company try to produce the best and the cheapest model in that particular segment in the shortest possible time. It is a very tedious process to design and manufacture a new model vehicle in a very small time span. This involves the co-operative efforts from different manufacturing and design organizations. Most of the big automobile companies present in India has only the assembly units present in their premises. However it is difficult to house all the components manufacture in one roof. Those companies outsource their designs to other small companies for the component manufacturing. These small companies will be given the required data and information of the product to be manufactured. It is their responsibilities to manufacture the tools and produce the components according to the customer specification. This work was carried out for the design and manufacture of three components for the Heater core support. The customer wanted us to become the vendors for the supply of heater core used in the AC unit in the multicylinder engine.

\section{EXPERIMENTAL STUDY}

Component name: Bottom tank

Customer details: Tata Toyo Radiators

Material: Multilayered aluminium strip of grade

Sheet thickness: $1 \mathrm{~mm}$

Mass: $\quad 0.0268 \mathrm{Kg}$

Application: Heater core in A.C unit

Number of tools required: 4 


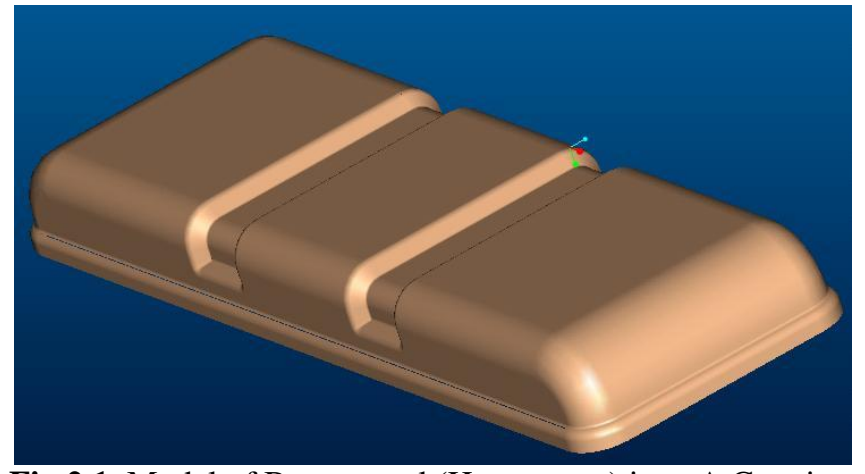

Fig.2.1. Model of Bottom tank(Heater core) in a A.C. unit

The scope of this work involves the design and preparation of assembly and detailed drawings for the sheet metal tools, providing Wire cutting data, Trimming profile calculation, 3D CAD Data for the manufacture of the components.

The no. of tools required for the component to be made were finalized after the study made on the component According to details provided, the following tools were finalized.

1) Draw tool.

2) Setting tool.

3) Trimming tool.

4) Skirt draw tool.

\section{DESIGN CALCULATIONS}

\subsection{Drawing Force Calculation:}

$\mathrm{F}_{\mathrm{Z}}=\mathrm{C} \cdot \mathrm{S} . \sigma_{\mathrm{B}} \sqrt{\mathrm{A}}$

Where $S=$ thickness of sheet in $\mathrm{mm}$

$\sigma_{\mathrm{B}}=$ ultimate tensile strength in $\mathrm{kg} / \mathrm{mm}^{2}=170 \mathrm{~N} / \mathrm{mm}^{2}$

$\mathrm{C}=3$ $\mathrm{A}=$ forming area $=8157.27 \mathrm{~mm}^{2}$

$\mathrm{F}_{\mathrm{Z}}=3 \times 1 \times 170 \mathrm{X} \sqrt{8157.27}$

$=46061.9 \mathrm{~N}$

$=4.6$ tons

\subsection{Blank Holding Force:}

Blanking holding force is usually taken as $33 \%$ of drawing force.

$\mathrm{F}_{\mathrm{B}}=33 \%$ of 4.6

$=1.518$ tons.

Total force required for drawing

$\operatorname{Total}(\mathrm{F})=4.6+1.5+$ factor of $\operatorname{safety}(20 \%)$

$$
=7.32 \text { tons. }
$$

\subsection{Trimming Tool:}

Cutting clearance $=\mathrm{c} \times \mathrm{s} \times\left(\sqrt{\mathrm{T}_{\max }} / 10\right)$

$\mathrm{C}=$ constant value is 0.005

$\mathrm{S}=$ sheet thickness

$=1 \mathrm{~mm}$

$\mathrm{T}_{\max }=$ shear strength of the stock material in N/mm $\mathrm{m}^{2}$ $170 \mathrm{~N} / \mathrm{mm}^{2}$

Therefore cutting clearance $=0.005 \times 1 \times(\sqrt{ } 170 / 10)$

$$
=0.02 \mathrm{~mm}
$$

\subsection{Cutting Force:}

Cutting force $=$ LTS

Where $\mathrm{C}=$ cutting force in Newtons

$\mathrm{L}=$ Length of cutting edge in $\mathrm{mm}$

$\mathrm{T}=$ thickness of stock material in $\mathrm{mm}$

$\mathrm{S}=$ Shear strength of the stock material in $\mathrm{N} / \mathrm{mm}^{2}$

$\mathrm{L}=374.315 \mathrm{~mm}$

$\mathrm{T}=1 \mathrm{~mm}$

$\mathrm{S}=170 \mathrm{~N} / \mathrm{mm}^{2}$

Cutting force $=374.315 \times 1 \times 170$

$$
=6.36 \text { tons }
$$

\subsection{Trimming Profile Calculations:}

For the straight portions the bending formulas can be applied

For the corners the draw formulas are applied

\subsubsection{Bending At the Straight Sides:}

Bend length $\mathrm{L}_{0}=(\pi \mathrm{X} \alpha / 180)\left(\mathrm{R}_{\mathrm{i}}+(\mathrm{s} \mathrm{X} \xi / 2)\right)$

Where $\mathrm{L}_{\mathrm{o}}=$ original length

$\mathrm{R}_{\mathrm{i}}=$ Internal radius

$$
=0.5 \mathrm{~mm}
$$

$\xi=$ Correction factor (to be chosen from graph shown in page )

$$
\begin{aligned}
& =0.5 \\
\mathrm{~s} & =\text { sheet thickness } \\
& =1 \mathrm{~mm} \\
\alpha & =\text { Bend angle } \\
& =90^{\circ}
\end{aligned}
$$

Substituting in the above equation

$$
\begin{aligned}
\mathrm{L}_{0} & =(\pi \times 90 / 180)(0.5+(1 \times 0.5 / 2)) \\
& =1.178 \mathrm{~mm}
\end{aligned}
$$

\subsubsection{Draw Calculation At The Corners}

$$
\begin{aligned}
& \mathrm{D}=\sqrt{ }\left(\mathrm{d}_{2}^{2}+2.28 \mathrm{rd}_{1}-0.56 \mathrm{r}^{2}+4 \mathrm{~d}_{2} \mathrm{~h}\right) \\
& \mathrm{d}_{2}=11.2 \mathrm{~mm} \\
& \mathrm{r}=1 \mathrm{~mm} \\
& \mathrm{~d}_{1}=9.2 \mathrm{~mm} \\
& \mathrm{~h}=1.654 \mathrm{~mm} \\
& \text { Substituting in the above equation } \\
& 11.2 \times 1.654 \text { ) } \\
& =15.28 \mathrm{~mm} \\
& =15.28 / 2 \\
& =7.64 \mathrm{~mm}
\end{aligned}
$$$$
\mathrm{D}=\sqrt{11.2^{2}}+(2.28 \times 1 \times 9.2)-\left(0.56 \times 1^{2}\right)+(4 \times
$$

\subsection{Skirt Draws Calculations:}

Force required for the operation can be divided into two. The bending force at the straight edges and drawing force at the corners. 


\subsubsection{Bending Force Calculation:}

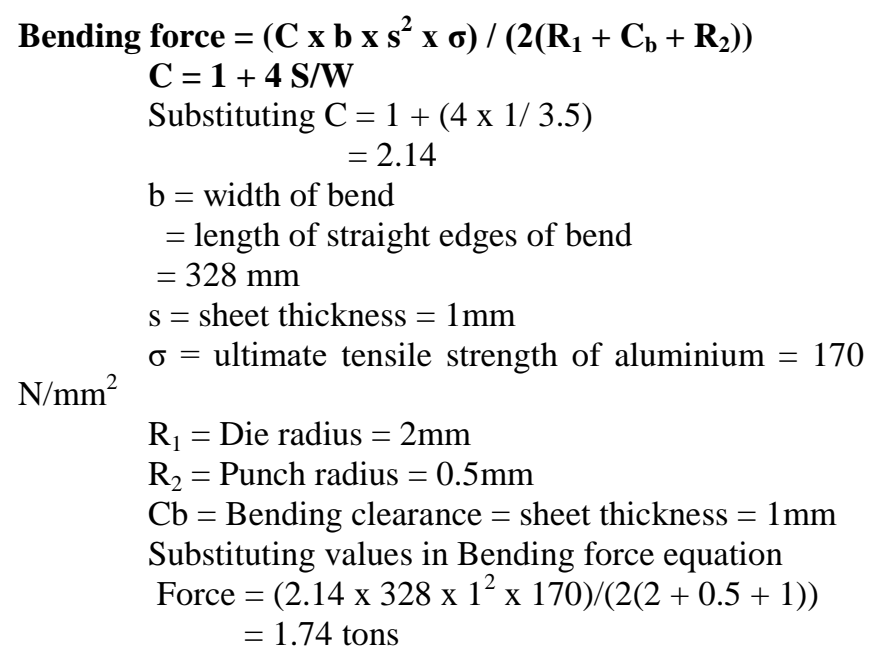

\subsubsection{Drawing Force Calculations:}

Since the 4 corners constitute one cup shape the drawing formulae for cups can be applied at the corners.

Draw force $=\pi \times \mathrm{d} \times \mathrm{s} \times \sigma_{\mathrm{u}} \times \mathrm{a}$

Where $\mathrm{d}=$ diameter of the cup in $\mathrm{mm}=11.2 \mathrm{~mm}$ $\mathrm{s}=$ Sheet thickness $=1 \mathrm{~mm}$

$\sigma_{\mathrm{u}}=$ Ultimate strength of material $=170 \mathrm{~N} / \mathrm{mm}^{2}$

$\mathrm{a}=$ constant varies according to the $d / D$ values where $d$ is the diameter of the cup and $\mathrm{D}$ is the diameter of the blank.

$\mathrm{d} / \mathrm{D}=11.2 / 16.1=0.695$

Therefore $\mathrm{a}=0.6$

Substituting in the equation

Force $=3.14 \times 11.2 \times 1 \times 170 \times 0.6$

$$
=0.358 \text { tons. }
$$

Total force required $=1.74+.358+$ Factor of safety $(20 \%)$

$$
=2.5 \text { tons. }
$$

\section{CONCLUSIONS}

A systematic approach has been followed in the design of press tools for bottom tank. The design and development has been successfully completed with following results.

1. The tool design was carried out as per the customer requirement and trials were taken before delivering the die.

2. Design calculations for all the four tools were considered for profressive tool deign.

3. Capacity of the machine was 2.5 tons which iswithin the safer design limit.

4. Die design was carried out as per DME and HASCO Standards.

\section{REFERENCES:}

[1]. P. Postawa, J. Koszkul; Influence of processing conditions on changing of shrinkage and mass POM injection molding parts; AMME, P16-19, May 2005.

[2]. P. Kennedy, Flow analysis of Injection Molds, HanserGardener,P 205-211,1995.

[3]. C.L. Tucker III, Computer modeling for polymer processing, Hanser publishers, Munich, Vienna, New York,P66-75,1989
[4]. Ozdemir, O.Uluer, A. Guldas, Flow front advancement of molten thermoplastic.

[5]. Schuller; Metal forming hand book.

[6]. David A Smith; Die design hand book

[7]. Donaldson; Tool Design

[8]. Roger Pearce ; Sheet metal forming 